\title{
Conflitos entre pessoas e animais silvestres no Semiárido paraibano e suas implicações para conservação
}

\author{
Lívia Emanuelle Tavares Mendonça ${ }^{1 *}$, Caroline Mendes Souto ${ }^{2}$, Lyuska Leite Andrelino ${ }^{2}$, Wedson de \\ Medeiros Silva Souto ${ }^{1}$, Washington Luiz da Silva Vieira ${ }^{1} \&$ Rômulo Romeu Nóbrega Alves ${ }^{2}$
}

${ }^{1}$ Programa de Pós-graduação em Ciências Biológicas, Universidade Federal da Paraíba, CCEN, DSE, Cidade Universitária, 58059-900, João Pessoa, Paraíba, Brasil.

${ }^{2}$ Departamento de Biologia, Universidade Estadual da Paraíba, Avenida das Baraúnas, 351, Bodocongó, 58019-753, Campina Grande, Paraíba, Brasil.

\begin{abstract}
Resumo - Ao longo da sua história, o ser humano tem se utilizado dos animais de diferentes formas, evidenciando sua importância e refletindo-se em atitudes de respeito, admiração e afeto. Contudo, algumas atitudes ligadas ao domínio, à exploração, ao medo e à aversão para com os animais silvestres têm gerado conflitos entre as populações humanas e a vida selvagem. Esse conflito é uma questão de conservação disseminada, porém estudos sobre o tema são escassos quando se trata de ambientes semiáridos como a Caatinga. Diante disso, a presente pesquisa objetivou documentar as atividades de caça voltadas para o controle de animais considerados perigosos e/ou causadores de prejuízos para a comunidade de uma área do Semiárido no interior da Paraíba, Região Nordeste do Brasil. A pesquisa foi realizada com 123 caçadores e excaçadores do município de Pocinhos, no período de 2007 a 2010, por meio de entrevistas com questionários semiestruturados, complementadas com conversas informais. Um total de 23 espécies de animais silvestres é abatido e os principais grupos envolvidos foram mamíferos (sobretudo os carnívoros) $(n=7$ espécies), répteis (sobretudo as serpentes) $(n=13)$ e, em menor escala, aves. Os motivos que geram os conflitos e levam ao abate dos animais silvestres são: ataque a criações domésticas, risco de morte às pessoas, destruição das lavouras e risco de transmissão de doenças. Apesar de serem pouco frequentes, os danos causados por animais silvestres geram intolerância generalizada entre os caçadores locais, incentivando a morte indiscriminada desses animais. Por isso tornam-se imprescindíveis programas de educação ambiental entre a população objetivando a manutenção de recursos faunísticos locais.
\end{abstract}

Palavras-chave adicionais: caça, carnívoros, controle, serpentes, vida selvagem.

\begin{abstract}
Conflicts between people and wild animals in semiarid areas of Paraíba and their implications for conservation) - Throughout their history, humans have utilized animals in different ways, demonstrating their importance and reflecting attitudes of respect, admiration and affection. However, some attitudes related to control, exploitation, fear and aversion regarding wild animals have produced conflicts between human populations and nature. This conflict is of widespread conservation interest, but studies on this subject are scarce amongst those covering semiarid environments such as the Caatinga. Therefore, the aim of the present study was to document the hunting activities geared towards the control of animals considered dangerous and/or causes of damage to the community of a semiarid area in the interior of Paraíba, in the northeast of Brazil. The study involved 123 hunters and ex-hunters from the municipality of Pocinhos. Between 2007 and 2010, interviews using semi-structured questionnaires were conducted, supplemented by informal conversations. A total of 23 species of wild animals were hunted and the main groups were mammals (particularly carnivores) ( $\mathrm{n}=7$ species) and reptiles (particularly snakes) $(n=13)$ and, to a lesser extent, birds. The reasons for the conflicts that led to the killing of wild animals were: attacks on livestock; risk of killing people; destruction of crops, and the risk of transmitting disease. Although infrequent, damage caused by wild animals generates widespread intolerance amongst local hunters, encouraging indiscriminate killing of these animals. Environmental education programs for the public are essential in order to maintain local wildlife resources.
\end{abstract}

Additional key words: hunting, carnivores, control, snakes, wildlife.

A conexão entre seres humanos e animais é antiga e extremamente relevante para as sociedades humanas, uma vez que essas mantêm estreitas relações de dependência e codependência dos recursos faunísticos (Baker 1930; Alvard et al. 1997; Foster \& James 2002; Silvius et al. 2004; Alves et al. 2010a). Ao longo da sua história, o ser humano tem se utilizado dos animais de diferentes formas, evidenciando a importância destes e refletindo-se em atitudes de respeito,

\footnotetext{
*Autora para correspondência: livia.etm@gmail.com

Editora responsável: Cecilia de Fatima C. B. Rangel de Almeida

Recebido: 16 maio 2011; aceito: 11 Ago 2011.
}

admiração e afeto (Hoover 1998; Franke \& Telecky 2001; Alves \& Souto 2010; Alves et al. 2010a,b). Muitas destas atitudes são afetadas pelo estilo de vida da pessoa e da visão que ela tem do lugar que o ser humano ocupa na natureza (Nie 2001). Contudo, algumas atitudes ligadas ao domínio, à exploração, ao medo e à aversão para com os animais silvestres têm provocado impactos graves sobre muitas espécies (Eagles \& Muffitts 1990; Newmark et al. 1994; Bizerril 2004), gerando conflitos entre as populações humanas e a vida selvagem em diferentes países do mundo (Yom-Tov et al. 1995; Sagor et al. 1997; Naughton-Treves 
1998; Sekhar, 1998; Stahl et al. 2001; Sillero-Zubiri \& Laurenson 2001; Mazzolli et al. 2002; Rao et al. 2002; Alves et al. 2009).

Esse conflito ocorre quando as necessidades e o comportamento da vida selvagem geram impactos negativos para os objetivos dos seres humanos (danos à colheita, ferimento ou morte de animais domésticos, ameaça ou morte de pessoas) ou quando os objetivos humanos geram impactos negativos para as necessidades da vida selvagem (Kaltenborn et al. 2006), como por exemplo a redução de hábitat e a caça. Ele representa um problema histórico e que atinge todas localidades onde o homem convive próximo a predadores (e.g., Guggisberg 1975; Rabinowitz 1986; Quigley \& Crawshaw 1992; Hoogesteijn et al. 1993; Lourival \& Fonseca 1997).

No Semiárido nordestino, o hábito de consumir animais silvestres é antigo. Durante as grandes secas periódicas, quando as safras agrícolas são frustradas e os animais domésticos dizimados pela fome e pela sede, a caça desempenha importante papel socioeconômico na região, por fornecer carne de alto valor nutritivo às famílias do sertão (Alves et al. 2009, 2010a). Além do uso da fauna como alimento, os animais servem para diferentes finalidades, tais como medicamentos, animais de estimação, em atividades culturais e para fins mágico-religiosos (Alves et al. 2009). Adicionalmente, algumas espécies são perseguidas e mortas por representarem riscos à saúde das pessoas ou das criações domésticas (e.g., serpentes peçonhentas e felinos) ou ainda por causarem prejuízos aos agricultores (e.g. aves granívoras, roedores e algumas espécies de mamíferos de médio porte que se alimentam de produto de plantações).

O conflito entre a vida selvagem e os humanos é uma questão de conservação disseminada e de crescente interesse para os conservacionistas (Kaltenborn et al. 2006). Estudos sobre esse tema são escassos quando se trata de ambientes semiáridos como a Caatinga (e.g. Alves et al. 2009, 2010a; Fernandes-Ferreira 2011). Diante disso, a presente pesquisa objetivou documentar as atividades de caça voltadas para o controle de animais considerados perigosos e/ou causadores de prejuízos para moradores do município de Pocinhos, situado no Semiárido Paraibano, Região Nordeste. Espera-se que os resultados possam subsidiar medidas que resultem em atitudes conservacionistas para as espécies-alvo, proporcionando uma relação menos conflituosa entre agricultores e caçadores com animais considerados nocivos.

\section{Material e Métodos}

Área de estudo. O município de Pocinhos ( $7^{\circ} 04^{\prime} 36^{\prime \prime} S$, $36^{\circ} 03^{\prime} 40^{\prime \prime}$ 'W) (Figura 1) está localizado no estado da Paraíba e possui área de $630 \mathrm{~km}^{2}$, abrigando cerca de 17.000 pessoas, das quais cerca de 7.400 estão concentradas na zona rural (IBGE 2010). A temperatura média anual é $23^{\circ} \mathrm{C}$, variando pouco durante o ano. Possui baixa pluviosidade, entre 400 e $600 \mathrm{~mm}$ anuais. O clima, semiárido quente com chuvas distribuídas entre o outono e o inverno, é do tipo mediterrâneo seco (Ribeiro 2003).

A vegetação desta unidade é formada por Florestas Subcaducifólia e Caducifólia, próprias das áreas agrestes. A fertilidade dos solos é bastante variada, com certa predominância de média para alta (CPRM 2005). Os dados agropecuários do município incluem lavouras temporárias com produção principalmente de milho e feijão e de mamona e batata-inglesa, essas últimas voltadas especialmente para a venda. Para a pecuária, houve um crescimento significativo
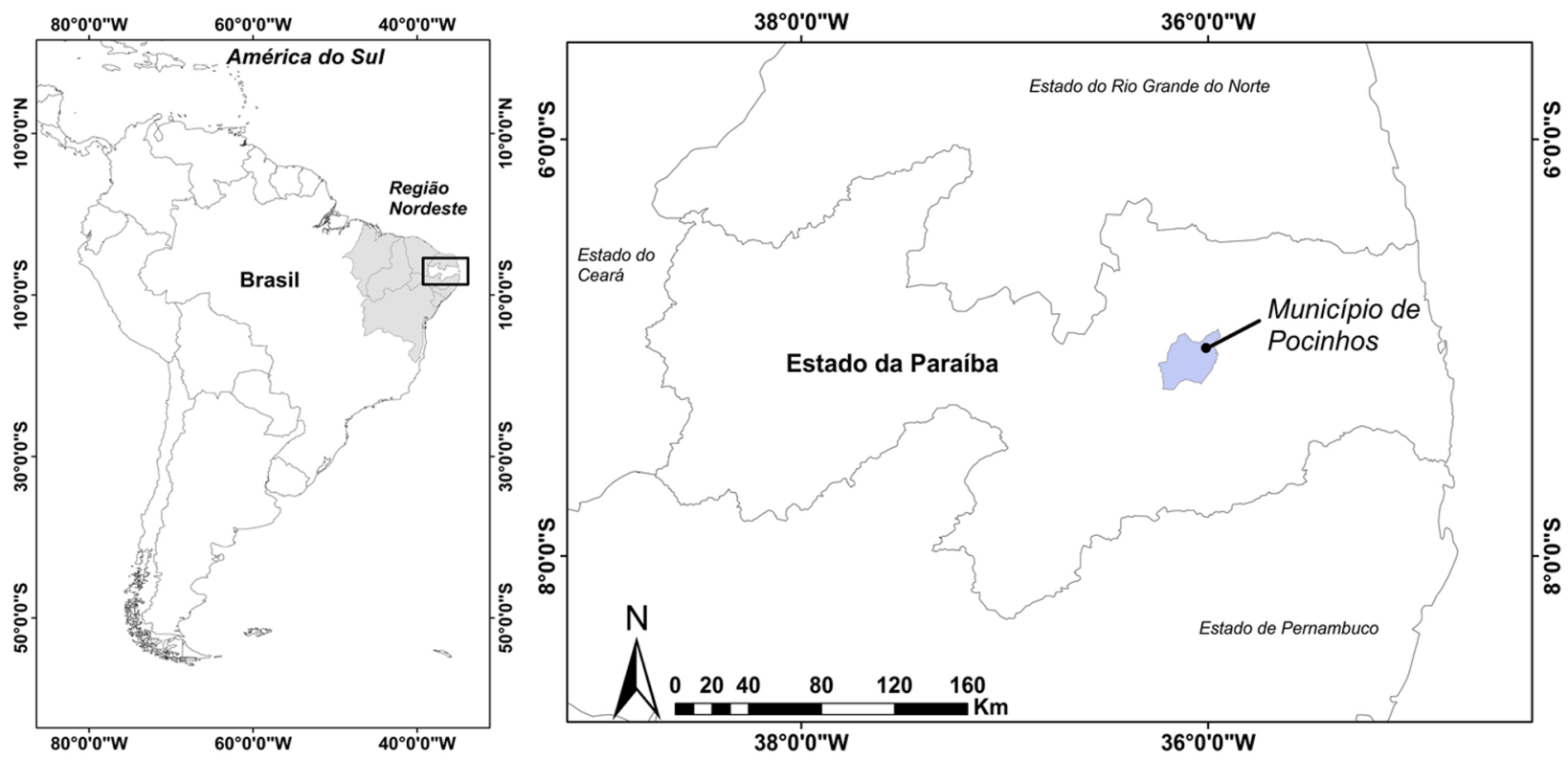

Figura 1. Localização do município de Pocinhos, estado da Paraíba, Brasil. 
de criação de aves desde 1995, enquanto o número de cabeças para rebanhos bovino, caprino e ovino foi decrescente no mesmo período (IBGE 2006).

Procedimentos. A pesquisa foi realizada no período de 2007 a 2010. As informações sobre os conflitos entre as pessoas e animais silvestres na região foram obtidas por meio de questionários semiestruturados (Bernard 1994), complementados por entrevistas livres e conversas informais (Mello 2003; Albuquerque et al. 2010). A seleção dos informantes foi realizada por meio da técnica de amostragem "bola-de-neve" (snowball; Bailey 1994): a partir do contato inicial, um informante é reconhecido e indica outro que, por sua vez, indica mais um e assim, sucessivamente. Os questionários foram aplicados a moradores que caçam ou já caçaram e apresentaram perguntas sobre cada animal caçado (lugar de coleta, apetrechos usados na captura, entre outras), finalidade da caça e ainda questionamentos envolvendo aspectos socioeconômicos dos caçadores. Antes de cada entrevista foi explicada a natureza e os objetivos da pesquisa e solicitada a permissão aos entrevistados para registrar as informações. Foi entregue a cada entrevistado o Termo de Consentimento Livre e Esclarecido, elaborado em duas vias, sendo uma retida pelo entrevistado e outra pelo pesquisador responsável. A pesquisa foi aprovada pelo o Comitê de Ética em Pesquisa do Hospital Lauro Wanderley (Protocolo CEP/HULW n ${ }^{\circ}$ 103/10).

Buscando obter respostas fidedignas dos entrevistados, os primeiros contatos foram iniciados com um diálogo amistoso, envolvendo temas como o prazer da caça e do contato com a natureza, o sabor da carne de animais silvestres, a experiência passada ao longo das gerações. Conforme a conversa informal, foi tomando aspecto descontraído, as perguntas do questionário foram introduzidas. Além disso, realizou-se mais de um contato com os caçadores, a fim de estreitar os laços de confiança entre pesquisador e informante. Entre os entrevistados, foram escolhidos informantes-chave (caçadores mais experientes), selecionados pelo critério de "especialistas nativos", que são aquelas pessoas que se autorreconhecem e que são reconhecidas pela própria comunidade como culturalmente competentes (Hays 1976).

Para uma maior precisão no registro das técnicas de caça, preferências de espécies cinegéticas e outras informações relevantes, foram utilizados outros métodos da etnobiologia associadas com os questionários semiestruturados, as quais constituíram de turnês guiadas em atividades de caça e observação participante do tipo não-membro (Stebbins 1987). As turnês guiadas e as observações-participantes foram conduzidas de forma equitativa entre os caçadores que permitiram acompanhamento de caçada por parte do primeiro autor. Para mitigar possíveis efeitos do não registro ou ausência de veracidade acerca de uma técnica de caça, por exemplo, nós utilizamos a confirmação sincrônica das informações
(Marques 1991), quando foram checadas as informações conferidas por um caçador com outros.

As observações participantes foram realizadas nos últimos meses de pesquisa, após o pesquisador adquirir maior vínculo de confiabilidade entre os caçadores, sendo acompanhados apenas aqueles que fizeram convite para tal prática $(n=3)$. Dessa forma, buscou-se diminuir as chances de se obter informações distorcidas sobre as atividades cinegéticas. Foram entrevistados 123 caçadores, sendo que destes, 95 (79\%) moram em área urbana, mas se deslocam frequentemente para áreas rurais para prática de atividades cinegéticas.

Para adquirir os nomes dos animais caçados pelos entrevistados foi adotada a técnica lista livre, que parte do princípio de que os elementos culturalmente mais importantes aparecem em muitas das listas em uma ordem de importância cultural (Weller \& Romney 1988). No entanto, uma vez que os informantes podem não compreender o que o entrevistador pretende extrair do conhecimento deles (Weller \& Romney 1988) ou os mesmos podem esquecer-se de itens da lista (Brewer 2002), técnicas adicionais foram aplicadas com os entrevistados para enriquecer as informações contidas na lista livre. Seguindo Brewer (2002) foi feita a indução não específica (nonspecific prompting), que consiste em induzir aos informantes a listarem itens de forma mais completa possível e os estimula a continuar pesquisando suas memórias quando eles poderiam parar, e a nova leitura (reading back), a qual se fundamenta na repetição lenta para o informante dos itens que ele mencionou na lista livre.

Os nomes vernaculares dos espécimes caçados foram registrados como citados pelas pessoas entrevistadas e os animais identificados das seguintes formas: 1- análise dos espécimes ou partes destes doados pelos entrevistados; 2análise de fotografias dos animais feitas durante as entrevistas e durante o acompanhamento das atividades de caça; 3- através dos nomes vernaculares, com o auxílio de taxonomistas familiarizados com a fauna da área de estudo e; 4- baseado em estudos etnozoológicos previamente realizados na área da pesquisa (ver Alves \& Rosa 2006; Alves et al. 2009; Confessor et al. 2009).

\section{Resultados E Discussão}

O perfil socioeconômico dos entrevistados é apresentado na Tabela 1. Nossos resultados revelaram que 23 espécies de animais silvestres são abatidas por representarem riscos ou causarem prejuízos (Tabela 2). Os grupos envolvidos em conexões conflituosas com os moradores locais são: répteis (sobretudo serpentes) $(\mathrm{n}=$ 13), mamíferos (sobretudo carnívoros) $(n=7)$ e aves $(n=3)$. Essa mesma tendência tem sido observada em outras localidades no Brasil e no mundo, onde esses grupos animais coabitam com seres humanos e frequentemente são 
Tabela 1. Perfil socioeconômico dos entrevistados, município de Pocinhos, estado da Paraíba, Brasil, entre 2007 e 2010.

\begin{tabular}{ll} 
Sexo & $\mathbf{n}(\%)$ \\
\hline Homens & $121(98,37)$ \\
\hline Mulheres & $2(1,62)$ \\
\hline Idade & $36(29,26)$ \\
\hline Até 29 anos & $27(21,95)$ \\
\hline 30-39 & $11(8,94)$ \\
\hline $\mathbf{4 0 - 4 9}$ & $19(15,44)$ \\
\hline $\mathbf{5 0 - 5 9}$ & $15(12,19)$ \\
\hline $\mathbf{6 0 - 6 9}$ & $15(12,19)$ \\
\hline Mais de $\mathbf{7 0}$ anos & \\
\hline Renda mensal* &
\end{tabular}

\section{Renda mensal*}

\begin{tabular}{lc}
\hline Não possui renda & $29(23,57)$ \\
\hline Até 1 salário mínimo & $30(24,39)$ \\
\hline 1 a 2 salários mínimos & $51(41,46)$ \\
\hline 2 a 3 salários mínimos & $7(5,69)$ \\
\hline 3 a 4 salários mínimos & $4(3,25)$ \\
\hline 4 a 5 salários mínimos & $2(1,62)$
\end{tabular}

Escolaridade

\begin{tabular}{ll} 
Analfabeto & $56(45,52)$ \\
\hline Ensino fundamental incompleto & $50(40,65)$ \\
\hline Ensino fundamental completo & $5(4,06)$ \\
\hline Ensino médio completo & $12(9,75)$ \\
\hline
\end{tabular}

*Salário mínimo vigente: $\mathrm{R} \$=545,00$

envolvidos em conflitos com os mesmos (e.g., Ruelle \& Bruggers 1982; Rabinowitz 1986; Silveira 1999; Mazzolli et al. 2002; Perez \& Pacheco 2006; Trinca \& Ferrari 2006; Hurtado 2007; Alves et al. 2010a,b; Fernandes-Ferreira 2011; Vieira 2011). Os carnívoros, por serem predadores de vertebrados, inclusive domésticos, e os répteis, que em várias localidades são considerados verdadeiras pragas e seres malignos, motivando seu extermínio pelas pessoas, representando perigo à saúde dos humanos ou de seus animais domésticos, são táxons frequentemente envolvidos em relações conflituosas (Alves et al. 2009, 2010a; SantosFita et al. 2010). Como resultado, várias espécies de carnívoros e cobras têm sofrido perseguição humana, algumas vezes levando-as ao perigo de extinção.

Dentre os carnívoros mencionados pelos entrevistados, os que se destacam e tiveram maior número de citações foram: gato-do-mato-pintado (33 citações), gatodo-mato-vermelho (32) e raposa (22) (para classificação e nomes científicos, ver Tabela 2), mortos por serem predadores de animais domésticos, implicando em prejuízos aos proprietários. Esse resultado não é surpresa, considerando que os carnívoros constituem o principal grupo de predadores de vertebrados nos ecossistemas terrestres (Pitman et al. 2002; Cheida et al. 2006). Não obstante, outras três espécies de mamíferos também foram citadas pelos entrevistados, embora com menor frequência: timbu, tamanduá e guaxinim, mortos por representarem risco à saúde das pessoas ou à vida dos animais domésticos.

O conflito entre carnívoros e humanos tem sido registrado em diferentes localidades no Brasil. Cavalcanti et al. (2010) trata sobre esse assunto sob várias perspectivas, entre elas a percepção e atitudes dos fazendeiros para com os felinos e os vários fatores que podem moldar as crenças humanas e seu comportamento em relação a esses predadores. Já outros estudos documentam perdas dos pecuaristas devido aos ataques de carnívoros às criações domésticas. Schaller (1976), por exemplo, relata que em um ano, somente no interior e entorno do Parque Nacional das Emas (estado de Goiás), foram mortas 56 onças-pardas [Puma concolor (Linnaeus, 1771)] com o fim de eliminar prejuízos aos rebanhos domésticos. Na mesma região, anos depois, Silveira (1999) registrou 14 ataques de onças-pardas, e dois ataques de onças-pintadas [Panthera onca (Linnaeus, 1758)] sobre bovinos (bezerros) em propriedades rurais no período de um ano e meio. Fernandes-Ferreira (2011), que realizou trabalho sobre as atividades cinegéticas na APA da Serra de Baturité, Ceará, registrou que carnívoros são frequentemente abatidos como forma de controle em virtude de ataques aos humanos e animais domésticos, sendo essa a principal motivação de caça de animais desse grupo na área pesquisada. Michalski et al. (2006) registrou a morte de 110-150 onças no período de 12 meses por caçadores profissionais de predadores no sul da Amazônia. Hurtado (2007), em estudo sobre a predação de criações domésticas por lobo-guará [Chrysocyon brachyurus (Illiger, 1815)] no entorno do Parque Nacional da Serra da Canastra, Minas Gerais, documentou a citação de ataques a essas criações em $70 \%$ das entrevistas com moradores locais.

No caso dos répteis, embora algumas espécies tenham valor utilitário, a maioria deles é morta por serem considerados nocivos às pessoas e aos animais domésticos. Nesse caso, as serpentes merecem destaque e todas são mortas, independente de serem ou não peçonhentas. $\mathrm{O}$ número de espécies envolvidas nos conflitos tende a ser ainda maior do que o citado $(n=12)$ porque os entrevistados não diferenciam a riqueza de espécies de ofídios que ocorrem na região. Vieira (2011), por exemplo, registrou 22 espécies de serpentes na Reserva do Patrimônio Natural Fazenda Almas, situada no semiárido paraibano, sendo também observada relação conflituosa entre estas e a população local. A mesma situação foi registrada por Alves et al. (2009), 
Tabela 2. Animais caçados por representarem riscos ou prejuízos aos caçadores, frequência de citações e categorias de uso das espécies: Aalimentação, B- uso medicinal, C- uso veterinário, D- uso ornamental, E- uso em simpatias, F- animal de estimação. município de Pocinhos, estado da Paraíba, Brasil.

\begin{tabular}{|c|c|c|c|c|}
\hline Família & Espécie & Conflito & $\begin{array}{l}\% \text { de } \\
\text { citações }\end{array}$ & $\begin{array}{l}\text { Categorias } \\
\text { de uso }\end{array}$ \\
\hline \multicolumn{5}{|l|}{ RÉPTEIS } \\
\hline \multirow[t]{2}{*}{ Viperidae } & $\begin{array}{l}\text { Caudisona durissa (Linnaeus, 1758) } \\
\text { Cobra-cascavel }\end{array}$ & $\begin{array}{l}\text { Representa risco de vida a pessoas e animais } \\
\text { domésticos }\end{array}$ & 39,4 & $\mathrm{~B} / \mathrm{C} / \mathrm{D} / \mathrm{E}$ \\
\hline & $\begin{array}{l}\text { Bothropoides erythromelas (Amaral, 1923) } \\
\text { Jararaca }\end{array}$ & $\begin{array}{l}\text { Representa risco de vida a pessoas e animais } \\
\text { domésticos }\end{array}$ & 22,7 & - \\
\hline \multirow[t]{2}{*}{ Boidae } & $\begin{array}{l}\text { Epicrates assisi (Machado, 1944) } \\
\text { Salamanta }\end{array}$ & $\begin{array}{l}\text { Representa risco de vida a pessoas e animais } \\
\text { domésticos }\end{array}$ & 31,8 & A \\
\hline & $\begin{array}{l}\text { Boa constrictor Linnaeus, } 1758 \\
\text { Jibóia }\end{array}$ & $\begin{array}{l}\text { Representa risco de vida a pessoas e animais } \\
\text { domésticos }\end{array}$ & 6,1 & - \\
\hline Teiidae & $\begin{array}{l}\text { Tupinambis merianae Duméril \& Bibron, } 1839 \\
\text { Teju }\end{array}$ & $\begin{array}{l}\text { Alimenta-se de ovos de galinha, causando } \\
\text { prejuízos }\end{array}$ & 6,1 & $\mathrm{~A} / \mathrm{B} / \mathrm{C} / \mathrm{E} / \mathrm{F}$ \\
\hline Colubridae & $\begin{array}{l}\text { Oxybelis aeneus Wagler, } 1824 \\
\text { Cobra-de-cipó }\end{array}$ & $\begin{array}{l}\text { Representa risco de vida a pessoas e animais } \\
\text { domésticos }\end{array}$ & 1,5 & - \\
\hline \multirow[t]{3}{*}{ Dipsadidae } & $\begin{array}{l}\text { Philodryas nattereri Steindachner, } 1870 \\
\text { Cobra-corre-campo }\end{array}$ & $\begin{array}{l}\text { Representa risco de vida a pessoas e animais } \\
\text { domésticos }\end{array}$ & 7,6 & - \\
\hline & $\begin{array}{l}\text { Boiruna sertaneja Zaher, } 1996 \\
\text { Cobra-preta }\end{array}$ & $\begin{array}{l}\text { Representa risco de vida a pessoas e animais } \\
\text { domésticos }\end{array}$ & 4,5 & - \\
\hline & $\begin{array}{l}\text { Xenodon merremi Wagler, } 1824 \\
\text { Jararaquinha-goipeba }\end{array}$ & $\begin{array}{l}\text { Representa risco de vida a pessoas e animais } \\
\text { domésticos }\end{array}$ & 3,0 & - \\
\hline \multirow[t]{4}{*}{ Elapidae } & $\begin{array}{l}\text { Micrurus ibiboboca } \text { Merrem, } 1820 \\
\text { Cobra-coral }\end{array}$ & $\begin{array}{l}\text { Representa risco de vida a pessoas e animais } \\
\text { domésticos }\end{array}$ & 21,2 & - \\
\hline & Cobra verde fina (não identificada) & $\begin{array}{l}\text { Representa risco de vida a pessoas e animais } \\
\text { domésticos }\end{array}$ & 3,0 & - \\
\hline & Cobra verde grossa (não identificada) & $\begin{array}{l}\text { Representa risco de vida a pessoas e animais } \\
\text { domésticos }\end{array}$ & 1,5 & - \\
\hline & Cobra verde (não identificada) & $\begin{array}{l}\text { Representa risco de vida a pessoas e animais } \\
\text { domésticos }\end{array}$ & 1,5 & - \\
\hline \multicolumn{5}{|l|}{ AVES } \\
\hline Cathartidae & $\begin{array}{l}\text { Coragyps atratus (Bechstein, 1793) } \\
\text { Urubu }\end{array}$ & $\begin{array}{l}\text { Ataque a animais domésticos, especialmente } \\
\text { filhotes de ovinos e caprinos }\end{array}$ & 1,5 & E \\
\hline \multirow[t]{2}{*}{ Falconidae } & $\begin{array}{l}\text { Caracara plancus (J.F. Miller, 1777) } \\
\text { Carcará }\end{array}$ & Ataque a animais domésticos & 4,5 & - \\
\hline & Gavião (não identificada) & Ataque a animais domésticos & 4,5 & - \\
\hline \multicolumn{5}{|l|}{ MAMÍFEROS } \\
\hline Canidae & $\begin{array}{l}\text { Cerdocyon thous (Linnaeus, 1766) } \\
\text { Raposa }\end{array}$ & $\begin{array}{l}\text { Estragos a lavouras, especialmente de milho, } \\
\text { ataques a animais domésticos e possibilidade de } \\
\text { transmissão de doenças }\end{array}$ & 34,8 & $\mathrm{~B} / \mathrm{C} / \mathrm{D}$ \\
\hline Didelphidae & $\begin{array}{l}\text { Didelphis albiventris Lund, } 1840 \\
\text { Timbu }\end{array}$ & $\begin{array}{l}\text { Causa antipatia devido a aparência com ratos e } \\
\text { possibilidade de transmissão de doenças }\end{array}$ & 4,5 & A \\
\hline \multirow[t]{2}{*}{ Felidae } & $\begin{array}{l}\text { Leopardus tigrinus (Schreber, 1775) } \\
\text { Gato-do-mato-pintado }\end{array}$ & $\begin{array}{l}\text { Ataque a animais domésticos, principalmente } \\
\text { ovinos e caprinos }\end{array}$ & 50,0 & $\mathrm{~A} / \mathrm{D}$ \\
\hline & $\begin{array}{l}\text { Puma yagouaroundi (É.G. Saint-Hilaire, 1803) } \\
\text { Gato-do-mato-vermelho }\end{array}$ & $\begin{array}{l}\text { Ataque a animais domésticos, principalmente } \\
\text { ovinos e caprinos }\end{array}$ & 48,5 & $\mathrm{~A} / \mathrm{D}$ \\
\hline Myrmecophagidae & $\begin{array}{l}\text { Tamandua tetradactyla (Linnaeus, 1758) } \\
\text { Tamanduá }\end{array}$ & $\begin{array}{l}\text { Investem contra cães de caça, podendo feri -los } \\
\text { ou matá-los }\end{array}$ & 4,5 & $\mathrm{~A} / \mathrm{B}$ \\
\hline Procyonidae & $\begin{array}{l}\text { Procyon cancrivorus (Cuvier, 1798) } \\
\text { Guaxinim }\end{array}$ & $\begin{array}{l}\text { Representa risco de vida a pessoas e animais } \\
\text { domésticos }\end{array}$ & 3,0 & - \\
\hline
\end{tabular}

que realizaram estudo sobre caça no município de Pocinhos, e atestaram que os moradores locais não matam apenas serpentes peçonhentas, mas igualmente as nãopeçonhentas, como também os anfisbenídeos por possuírem um corpo alongado e desprovido de patas, semelhante a uma serpente. Estes animais despertam nas pessoas medo e repugnância, ou simplesmente são considerados potencialmente perigosos.

A mesma aversão aos répteis observada nesse trabalho tem sido registrada em várias localidades do Brasil. Moura et al. (2010) ressaltam que, em diversas regiões do país, há uma aceitação de um estereótipo negativo para todas as serpentes, que são geralmente consideradas "animais perigosos". Tal situação, associada a alguns aspectos da cultura popular, pode potencializar conflitos entre a espécie humana e as serpentes (Cardoso et al. 2003; Argôlo 2004; Alves et al. 2010c), influenciando negativamente o modo como as pessoas interagem com animais deste grupo (Vizotto 2003; Silva 2006). Em trabalho realizado no município de Pedra Branca, Bahia, Santos-Fita et al. (2010) registraram que os moradores locais têm um comportamento negativo forte em relação às serpentes, matando-as sempre que possível. As pessoas também costumam incluir anfisbenídeos na lista por terem uma 
morfologia similar às serpentes (Alves et al. 2010c; Fernandes-Ferreria 2011).

Os eventuais prejuízos causados pela morte de animais domésticos têm sido um motivo adicional para a perseguição às serpentes, além do estereótipo negativo comumente associado a esse grupo animal. Alves et al. (2010b) destacam que serpentes peçonhentas podem causar a morte de caprinos, ovinos e bovinos, levando a prejuízos significativos para os criadores rurais, um fator que estimula seu abate sempre que são encontradas. Trinca \& Ferrari (2006), em trabalho realizado no Estado do Mato Grosso, Brasil, relatam que alguns caçadores locais são a favor do extermínio de todos os predadores com potencial para atacar os humanos ou os animais domésticos, mesmo que estes predadores vivam no seu ambiente natural e longe dos humanos. Isso é reforçado pelo fato de muitas pessoas acreditarem que todas as cobras são perigosas e agressivas (Marcum 2007). Alves et al. (2010b), em revisão sobre as relações entre répteis e pessoas no Brasil, apontam que há relações conflituosas com pelo menos 29 espécies de répteis.

Além dos carnívoros e répteis, algumas espécies de aves podem atacar criações domésticas, especialmente filhotes de bovinos, caprinos e ovinos. Segundo os informantes, urubu e carcará bicam animais recém nascidos, principalmente na região dos olhos.

Fernandes-Ferreira (2011), em trabalho sobre caça, registrou os falconiformes como o principal grupo de aves causador de conflitos com moradores da Serra de Baturité, Ceará. De fato, falcões, gaviões e urubus (Bencke 2001) são aves de rapina consideradas topo de cadeia alimentar e predadores de diversos animais (Sick 1997). Embora possam atacar a animais domésticos e gerar conflitos, essas espécies foram pouco citadas no presente estudo.

Nenhum caçador mencionou a ocorrência de ataques de aves às plantações locais, apesar desse tipo de conflito ser comumente relatado em outros trabalhos. Por exemplo, Perez \& Pacheco (2006), em estudo sobre danos às culturas de subsistência numa região protegida da Bolívia, constataram que pássaros e macacos podem destruir até $70 \%$ das culturas locais. Já em Camarões, uma única espécie de ave foi registrada como responsável pela extipação de até $80 \%$ dos campos de lavouras, causando problemas significativos para os agricultores da região (Ruelle \& Bruggers 1982). Neste mesmo país, Weladji \& Tchamba (2003) registraram uma espécie de psitacídeo como uma das cinco principais causadoras de danos a culturas. $\mathrm{Na}$ área onde foi relizado o presente estudo, apesar de psitacídeos serem capturados para fins comerciais e criação doméstica (Alves et al. 2010a), não há relatos sobre danos causados por esses animais, mesmo sendo considerados importantes predadores de sementes (Janzen 1981; Galetti \& Rodrigues 1992; Renton 2001).

Os resultados indicam que, embora carnívoros, ofídios e aves sejam mortos em virtude das relações conflituosas discutidas acima, vários dos subprodutos dos animais mortos por esse motivo são aproveitados e podem ser utilizados de diferentes formas pelos moradores locais. Dependendo da espécie, os animais podem ser usados como alimento (e.g., teju, gatos-do-mato pintado e vermelho, e tamanduá), na preparação de remédios na medicina popular (e.g., cobra-cascavel, teju e raposa), suas peles são usadas como ornamento (e.g., gatos-do-mato pintado e vermelho) e podem ainda ter uso para fins mágico-religiosos (e.g., cobra-cascavel, teju e urubu).

Um bom exemplo é o teju, lagarto que pode trazer prejuízos às populações locais, uma vez se alimenta de ovos de aves domésticas, mas que por outro lado, é usado como alimento, e sua gordura e língua são utilizadas como remédios. Essa espécie é amplamente utilizada para diversos fins em várias localidades (Branch \& Silva 1983; Begossi 1992; Begossi \& Braga 1992; Alves \& Rosa 2006, 2007; Kaltenborn et al. 2006; Alves et al. 2007, 2009; Confessor et al. 2009; Oliveira et al. 2010; Souto et al. 2011).

Outro exemplo mencionado pelos caçadores é a raposa, morta por representar riscos à vida das pessoas e animais domésticos e também por atacar as lavouras, principalmente de milho (Zea mays L.). Por outro lado, o aproveitamento de subprodutos da raposa (banha, couro, rabo) na medicina tradicional e em simpatias mostra que a população local tira proveito da espécie. Da mesma forma, serpentes como a cascavel e a salamanta, que podem causar a morte de pessoas ou de criações domésticas, são empregadas localmente como remédio e alimento, respectivamente. Confessor et al. (2009), em estudo sobre etnoveterinária realizado com moradores da zona rural do município de Pocinhos, Paraíba, constatou o uso medicinal da raposa e da cascavel, corroborando os resultados encontrados em nosso estudo.

O tamanduá, morto por ser uma ameaça a cães de caça, tem sido caçado localmente por seu valor alimentício (Alves et al. 2009, 2010a), sendo esse uso amplamente documentado no Brasil (Andrigueto-Filho et al. 1998; Lisboa 2002; Rosas 2006; Nobre 2007; Alves et al. 2009; Hanazaki et al. 2009; Rezende \& Schiavetti 2010) e em outras regiões da América do Sul (Hill \& Padwe 2000; Bodmer \& Lozano 2001; Vargas 2002). Outros exemplos de animais mortos por representarem risco aos caçadores e que também são utilizados para outros fins, sejam eles alimentar, medicinal, ornamental ou de misticismo, são mostrados na Tabela 2.

Constata-se assim que uma mesma espécie pode tanto constituir uma fonte de recursos quanto pode representar uma possibilidade de perdas econômicas ou riscos à saúde. Essas constatações estão de acordo com Marques (1995), que ressalta o fato da conexão do homem com o componente zoológico ser permeada de contradições e ambiguidades.

Fatores que influenciaram o conflito na área pesquisada. Os conflitos entre animais selvagens e humanos manifestam-se de várias maneiras, conforme pode ser evidenciado na Tabela 2. Os motivos que geram os conflitos e levam ao abate dos animais silvestres são: ataque a 
criações domésticas, risco de morte às pessoas, destruição das lavouras e risco de transmissão de doenças. Motivações similares têm sido registradas em outras localidades (Sanyal 1987; Patterson et al. 1989; Vitousek et al. 1997; Mills \& Childs 1998; Saj et al. 2001; Packer et al. 2005; Thirgood et al. 2005) e são consideradas as principais causas de conflitos entre o homem e a vida silvestre (Thirgood et al. 2005). Foloma (2005) aponta ainda que os conflitos podem ter as seguintes causas: pessoas mortas e feridas por animais selvagens; perda de animais domésticos por ataque de animais selvagens; competição por áreas de pastagem e por água; incursões de animais selvagens nas propriedades das pessoas; ausência ou políticas inadequadas de compensação por perdas e/ou ferimentos a humanos; invasão de seres humanos em áreas de animais selvagens; bloqueio de rotas de migração de animais selvagens por humanos e; caça furtiva.

Ataque a criações domésticas. $\mathrm{O}$ ataque a criações domésticas foi a principal justificativa dos caçadores para abaterem os predadores. Gatos-do-mato (Puma yagoaroundi e Leopardus tigrinus) e raposas (Cerdocyon thous) são as espécies que representam maior ameaça às criações domésticas. Essas espécies também apresentaram as maiores frequências de citação, indicando sua importância no contexto de conflitos entre humanos e animais silvestres no Semiárido paraibano. Os animais domésticos alvos dos ataques são caprinos, ovinos e aves. Não foi registrada nenhuma menção de ataques a animais de maior porte, como bois ou vacas (Bos taurus Linnaeus, 1758), diferente dos resultados em diversas localidades no Brasil (Mazzolli et al. 2002; Conforti \& Azevedo 2003; Zimmermann et al. 2005; Michalski et al. 2006) e no mundo (Rabinowitz 1986; Hoogesteijn et al. 1993; Oli et al. 1994; Polisar et al. 2003). A ausência de predadores de grande porte na área estudada pode explicar essa constatação, uma vez que os felinos que ocorrem na área são de pequeno porte quando comparado a espécies comuns em outras regiões, como onças (Panthera onca e Puma concolor). A título de exemplo, o gato-domato-pintado, um potencial predador local, é o menor gato selvagem das Américas, pesando entre 2 e $3 \mathrm{~kg}$ e medindo entre 34 e $56 \mathrm{~cm}$ de comprimento total (Silveira 1999).
Muitas vezes, sequências de ataques às criações fazem com que os agropecuaristas locais contratem caçadores, conhecidos como "rastreadores", pois estes conseguem identificar o rastro deixado pelos carnívoros, perseguindoos, localizando-os e matando-os com arma de fogo. Foram entrevistados três caçadores rastreadores e um deles afirmou ter abatido cerca de 200 gatos-do-mato durante toda a vida. As diferenças entre as pegadas dos animais que foram citadas pelos caçadores são descritas na Tabela 3. Observa-se que a percepção e identificação das pegadas de predadores pelos caçadores apresentam certa concordância com as descrições encontradas na literatura. Por exemplo, segundo Carvalho Jr \& Luz (2008) nas pegadas do gato-do-mato-vermelho não é possível observar a marca das unhas do animal, já o rastro da raposa contém a marca bem evidente das unhas, confirmando o que foi colocado pelos caçadores no presente estudo. A observação dos caçadores em relação à diferença de tamanhos entre as pegadas do gatos-do-mato vermelho e pintado é coerente, uma vez que esta última espécie é a menor entre os Felídeos que ocorrem no Brasil, com proporções corporais semelhantes as do gato-doméstico (Oliveira e Cassaro 1999).

Os caçadores rastreadores detêm um amplo conhecimento sobre hábitos de vida das espécies alvo. Segundo eles, o gato-do-mato-pintado tem hábito noturno, dormindo durante o dia à sombra de facheiros (Cactaceae) e outras espécies vegetais da região, saindo à noite para caçar; já o gato-do-mato-vermelho, que é o maior predador de rebanhos segundo os entrevistados, tem hábito diurno. Essas informações estão de acordo com o que relata a literatura a respeito dessas espécies (Silveira 1999). Os caçadores afirmam que ao matar uma presa, o gato-do-mato costuma cobrir as carcaças com folhas e terra para uma alimentação subsequente. Esse comportamento foi descrito por Pitman et al. (2002) em estudo que caracteriza a predação de animais domésticos por carnívoros em diferentes regiões do Brasil. Os caçadores se aproveitam dessa característica particular do felino, para ficar de tocaia próximo ao alimento até que ele se aproxime. Devido ao faro aguçado apresentado por esses felinos, é comum rastreá-los em sentido contrário à direção do vento, para que não percebam a presença do

Tabela 3. Descrição dos diferentes tipos de pegadas de carnívoros identificadas por rastreadores no município de Pocinhos, estado da Paraíba, Brasil.

\begin{tabular}{|ll|}
\hline Animal & Características das pegadas \\
\hline $\begin{array}{l}\text { Puma yagouaroundi } \\
\text { (gato-do-mato-vermelho) }\end{array}$ & Rastro maior e mais leve, ou seja, menos marcado na terra. \\
& $\begin{array}{l}\text { Não é possível identificar a marca das unhas do animal no rastro. } \\
\text { Maior distância entre o rastro das patas dianteiras e traseiras. }\end{array}$ \\
\hline $\begin{array}{l}\text { Leopardus tigrinus } \\
\text { (gato-do-mato-pintado) }\end{array}$ & Rastro menor e leve. \\
& Não é possível identificar a marca das unhas do animal no rastro. \\
Merdocyon thous & Maior distância entre o rastro das patas dianteiras e traseiras. \\
(raposa) & É possível identificar a marca das unhas no rastro. \\
& $\begin{array}{l}\text { Menor distância entre o rastro das patas dianteiras e traseiras. } \\
\text { O rastro aparenta-se com pegadas de cachorro. }\end{array}$ \\
\hline
\end{tabular}


caçador.

Além do uso de arma de fogo, algumas armadilhas são empregadas na captura de predadores, são elas a arataca, a gaiola para carnívoros e o laço. A arataca consiste em uma armadilha de ferro com uma base arredondada e duas alças que se abrem sob pressão. No interior da arapuca, é colocada uma isca que varia de acordo com o animal que se deseja capturar. No momento em que o animal pisa na base redonda da armadilha, as duas alças se fecham prendendo sua perna. A gaiola para carnívoros é uma caixa feita de tábuas com uma porta que fecha por meio de um mecanismo guilhotina. Existe um compartimento visível na parte de trás da armadilha para manter uma isca viva (geralmente uma galinha). O laço é uma armadilha projetada para capturar o animal elevando-o do solo preso pelo pescoço. Todas essas armadilhas são descritas detalhadamente por Alves et al. (2009).

Além dos carnívoros, algumas espécies de aves podem atacar criações domésticas, especialmente filhotes de bovinos, caprinos e ovinos. O lagarto teju alimenta-se de ovos de galinha, produto amplamente comercializado localmente e utilizado na alimentação das famílias.

Constatou-se que os caçadores locais mantêm uma intima relação com seus cães de caça. Por isso, eles são favoráveis à morte de qualquer animal que possa ferir ou matar os cachorros. Nessa perspectiva, o tamanduá é a espécie mais temida. Ele utiliza suas garras para se defender dos cães, chegando até a matá-los em virtude de seu ataque defensivo. Segundo os caçadores, se isso acontecer, é necessário cortar os punhos do tamanduá para libertar o cão do “abraço mortal”. Fernandes-Ferreira (2011) também registrou situação similar entre caçadores da APA de Baturité, onde os tamanduás são abatidos com a finalidade de controle, já que representam um risco aos cães de caça, pois quando acuados, assumem postura de defesa e reagem cravando suas longas garras, podendo matá-los.

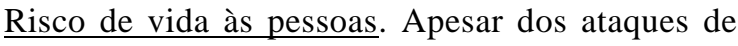
animais selvagens a seres humanos serem raros, eles têm impacto significativo em termos de geração de conflitos (Quigley \& Herrero 2005). Nesse contexto, as serpentes são os animais mais perseguidos, pois são temidas por representarem risco à vida das pessoas. A forte pressão dos caçadores sobre esse grupo de animais não é surpresa se considerarmos que uma das principais motivações para o abate de répteis está associada ao controle de espécies que ofereçam algum risco ao ser humano ou a animais domésticos, por serem consideradas peçonhentas ou potencialmente predadoras (Morris \& Morris 1965; Oliver 1968; Greene 1997; Andreu 2000; Alves et al. 2010a).

Apenas um caçador relatou ter sido vítima de acidente ofídico, ocorrido durante uma caçada. Ele foi picado na perna por uma jararaca e foi socorrido por um parceiro de caça, recebendo atendimento médico na cidade de Campina Grande, estado da Paraíba, a cerca de $40 \mathrm{~km}$ da região de estudo.
Apesar do número de acidentes com serpentes ser baixo entre o grupo estudado, a aversão e repulsa a esses animais é grande, evidenciando que a percepção humana do perigo representado por um animal pode não estar diretamente ligada ao real nível de ameaça que ele representa. Assim, o conflito entre o homem e as serpentes está mais relacionado a aspectos culturais e falta de conhecimento sobre as mesmas, do que à ocorrência efetiva de acidentes.

No discurso dos entrevistados, foi possível perceber que a maioria deles é favorável à morte de serpentes, não havendo distinção entre espécies peçonhentas e não peçonhentas. Essa percepção corrobora a observação de Argôlo (2004), o qual afirma que a presença de serpentes peçonhentas no mesmo ambiente que as pessoas gera conflitos. A generalização do estereótipo negativo para as serpentes contribui para a morte indiscriminada de espécies, sejam elas peçonhentas ou não (Moura et al. 2010). Entretanto, foi possível perceber que algumas espécies podem ser privadas da morte por alguns caçadores $(n=3)$. É o caso da cobra-preta, que segundo um caçador, além de não possuir peçonha, se alimenta de outras cobras, incluindo as peçonhentas.

Para prevenir acidentes ofídicos, os caçadores costumam utilizar botas e calças de couro durante as expedições à mata, prática semelhante ao que foi observado por Moura et al. (2010), que estudaram o relacionamento entre pessoas e serpentes no leste de Minas Gerais, Sudeste do Brasil. Esses procedimentos são tidos como corretos e efetivamente eficazes na prevenção de acidentes ofídicos (Feitosa et al. 1997). Além das serpentes, carnívoros como gatos-do-mato, guaxinim e raposa também são considerados pela população local como animais perigosos, que podem atacar seres humanos. Segundo os entrevistados, a raposa, em especial, é considerada agressiva, principalmente no período em que se encontra “choca”. Essa expressão é utilizada localmente para designar o estado da fêmea da espécie logo após o parto. Nessa época, segundo os caçadores, o animal fica muito raivoso podendo atacar pessoas. Apesar de nunca terem sido atacados por esses carnívoros, os caçadores locais os matam de maneira preventiva, apenas pela possibilidade de que possam causar problemas.

Ataque às lavouras. Mundialmente, existem relatos de animais caçados por trazerem danos às lavouras (Ruelle \& Bruggers 1982; Naughton-Treves 1998; Rao et al. 2002; Naughton-Treves \& Treves 2005; Perez \& Pacheco 2006). $\mathrm{Na}$ área estudada, a queixa dos caçadores quanto a esse conflito é somente associada à raposa, que invade as plantações de milho e alimenta-se das espigas, causando grandes estragos. Rocha et al. (2004) registraram a presença desse item no conteúdo alimentar da espécie. Além dessa planta, o animal também pode alimentar-se de frutos de outras espécies, como melancia e pepino-do-mato. Segundo um agricultor local, essa espécie pode se alimentar de quaisquer itens plantados nos roçados. De fato, ela possui 
dieta bastante diversificada, podendo as frutas representar até cerca de 50\% de sua alimentação (Brady 1979). Como é considerada uma espécie oportunista, a raposa sobrevive em áreas degradadas e antrópicas (Langguth 1975; MottaJúnior et al. 1994, Facure \& Monteiro-Filho 1996), podendo dessa forma, se aproveitar de uma gama de possibilidades alimentares facilitadas pela aproximação do homem ao ambiente natural desses animais.

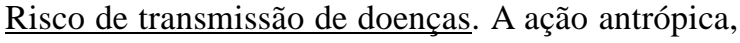
como a destruição de hábitats naturais para a agricultura e a criação de animais domésticos para o consumo humano e o acúmulo de lixo têm contribuído para atrair espécies selvagens para a proximidade do convívio humano (Alexander et al. 2002), aumentando a participação delas na transmissão de doenças. Na área pesquisada, o timbu é morto principalmente por representar um potencial transmissor de doenças aos seres humanos, segundo os moradores locais. Um dos motivos é que esse animal aparenta-se com ratos, causando aversão à população. De fato, diversos trabalhos têm demonstrado a participação da espécie no ciclo de transmissão de doenças como leishmaniose visceral, leishmaniose cutânea e doença de chagas (Sherlock et al. 1984; Jansen et al. 1991, 1997; Courtenay et al. 1994, 1996; Sherlock 1996; Llanos-Cuentas 1999; Zerpa et al. 2002; Cerqueira et al. 2003; Mohebali et al. 2005). Por outro lado, alguns caçadores $(n=7)$ afirmaram se alimentar desse animal, evidenciando que ele não causa antipatia generalizada na população local, podendo assim ter valor utilitário como outras espécies conflituosas.

Outra espécie potencial transmissora de doenças, segundo os entrevistados, é a raposa, que pode transmitir o vírus da raiva. De acordo com Carnieli et al. (2008), esta espécie de canídeo já foi identificada como reservatório do vírus na Região Nordeste. Além disso, corresponde ao principal reservatório silvestre da Leishmania chagasi Cunha \& Chagas, 1937 (leishmaniose) (Deane \& Deane 1955; Silveira et al. 1982; Lainson et al. 1990; Courtenay et al. 1994; Courtenay 1996). Outros estudos apontam mais doenças, das quais a raposa pode ser hospedeira; são elas cinomose (Jorge 2008), parvovírus (Curi 2005; Fiorello et al. 2007) e leptospirose (Souza Júnior et al. 2006).

Alguns estudos epidemiológicos mostram que espécies silvestres, como gato-do-mato-pintado, guaxinim e tatu-verdadeiro (Dasypus novemcinctus Linnaeus, 1758), este último altamente caçado na região para fins alimentares, podem estar envolvidos no ciclo de transmissão de doenças como parvovirose e leishmaniose (Lainson et al. 1982). No entanto, nenhuma dessas espécies foi apontada pelos caçadores como possível transmissora de doenças.

Aspectos conservacionistas. $O$ conflito entre humanos e animais silvestres é um tema de grande interesse para conservação, mais ainda em um cenário de crescimento populacional que resulta na expansão das atividades humanas (Woodroffe 2000; Conover 2002) e consequentemente na progressiva fragmentação e degradação dos hábitats. Como pode ser evidenciado no presente estudo, as relações conflituosas entre diversas espécies de animais silvestres e as pessoas tem sido um fator estimulador do abate de animais silvestres no Semiárido paraibano, de forma semelhante ao que tem sido registrado em outras localidades. Das 23 espécies registradas nesse estudo, oito estão listadas na IUCN (2011): Caracara plancus (carcará), Cerdocyon thous (raposa), Didelphis albiventris (timbu), Puma yagouaroundi (gato-do-matovermelho), Tamandua tetradactyla (tamanduá), Procyon cancrivorus (guaxinim), Tupinambis merianae (teju) e Leopardus tigrinus (gato-do-mato-pintado). Destas, as seis primeiras em categoria de menor preocupação. O lagarto $T$. merianae está listado como quase ameaçado e L. tigrinus encontra-se enquadrada na categoria vulnerável. Entre as atuais ameaças a essa espécie estão a perda de hábitat para criação de pastagens e plantações e a retaliação devido à predação de aves domésticas; este último fato confirmado no presente estudo. Outras espécies registradas nesse trabalho encontram-se em listas estaduais de espécies ameaçadas: T. tetradactyla, incluída na categoria vulnerável nos estados do Rio Grande do Sul e Minas Gerais, e $P$. yagouaroundi, vulnerável em São Paulo e Rio Grande do Sul (Chiarello et al. 2008).

Quando considerados os conflitos entre humanos e animais, a exemplo do que ocorre em outras localidades, os carnívoros estão entre os animais mais ameaçados, sendo mortos preventivamente. Entretanto, deve-se considerar que ataques a rebanhos domésticos estão direta ou indiretamente relacionadas a atividades antrópicas. Alguns estudos mostram que a vegetação ao redor das áreas onde se mantêm as criações pode influenciar a ocorrência de ataques por carnívoros (Jackson et al. 1996; Bangs \& Shivik 2001; Stahl \& Vandel 2001). Outros pesquisadores também reportam uma associação negativa entre a predação de animais domésticos por carnívoros e a densidade de estradas e povoados humanos (Robel et al. 1981 apud Treves et al. 2004; Jackson et al. 1996; Stahl \& Vandel 2001). Os predadores podem ter mais contato com criações domésticas ao serem reduzidas as áreas naturais e também na ausência de áreas de transição entre reservas, ou áreas protegidas, e propriedades rurais (Azevedo \& Conforti 2002). Na área pesquisada, assim como ocorre em outras áreas do Semiárido nordestino, a caatinga tem sido bastante modificada e, segundo Leal et al. (2005), é atualmente um dos biomas brasileiros mais alterados pelas atividades humanas. $\mathrm{O}$ uso inadequado dos recursos da caatinga tem causado danos ambientais irreversíveis, uma vez que o processo de desertificação já afeta cerca de $15 \%$ desse bioma (Schober 2002). A fragmentação e degradação dos hábitats implicam na redução das presas naturais, de forma que os predadores silvestres tendem a atacar criações domésticas.

A caça de vertebrados, por esporte ou para subsistência, é uma prática comum na área pesquisada (ver 
Alves et al. 2009), e certamente tem influenciado na disponibilidade de potenciais presas naturais dos mamíferos carnívoros que ocorrem na área, os quais vêm sendo vitimas do abate por serem considerados nocivos. Por exemplo, a raposa alimenta-se predominantemente de frutos, seguido de pequenos mamíferos, serpentes e aves. Entre as possíveis presas desse animal estão as aves Nothura maculosa (Temminck, 1815) e Leptotila sp. (Rocha et al. 2004) que são bastante caçadas para fins alimentares na região pesquisada. $\mathrm{O}$ gato-do-mato-pintado tem como dieta preferencial, pequenos mamíferos, como observado por Olmos (1993) para a Caatinga, especialmente presas de hábitos noturnos e cursoriais. Já o gato-do-mato-vermelho alimenta-se especialmente de espécies de hábito diurno, entre elas T. merianae (Rinaldi 2010) que corresponde a uma das espécies silvestres mais caçadas na região para fins alimentares e zooterápicos (Alves et al. 2009, 2010c, 2011; Confessor et al. 2009). Dessa forma, o aumento de ataques às criações domésticas também está diretamente ligado à pressão de caça às presas naturais, conforme apontam Rabinowitz (1986) e Redford (1992).

Além da forte pressão de caça, tanto sobre presas naturais como sobre os próprios predadores, o processo de desmatamento para a implementação da agropecuária aproxima ainda mais animais silvestres do homem e suas criações domésticas. Carnívoros silvestres jovens em busca do estabelecimento de seus territórios, fêmeas com filhotes, ou animais velhos, com dificuldades para caçar presas silvestres são mais propensos a "experimentar" novos itens alimentares representados por bovinos, ovinos, caprinos, suínos, equinos, etc. (Rabinowitz 1986).

A redução de predadores através da atividade antrópica pode gerar problemas ecológicos ainda maiores, que implicam novos conflitos entre pessoas e a fauna. Por exemplo, a eliminação de predadores de topo da cadeia alimentar como os felinos, pode influenciar diretamente a dinâmica das comunidades animais e indiretamente as comunidades vegetais (Redford 1992). Na ausência de predadores, suas presas naturais, como mamíferos herbívoros (veados), roedores (capivaras, ratos), aves (pombas), répteis (serpentes e lagartos) e insetos (gafanhotos) tendem a se multiplicar exponencialmente, podendo trazer sérios prejuízos à agricultura e consideráveis perdas financeiras (Pitman et al. 2002).

Conclusões e recomendações. Os mamíferos carnívoros e serpentes são os principais causadores de conflitos entre humanos e animais silvestres na área pesquisada. Esses animais atacam, sobretudo, criações domésticas geradoras de renda às famílias locais, além de representarem perigo às pessoas, o que estimula a aversão dos caçadores contra eles. Além dos carnívoros, outros mamíferos são mortos por atacarem cães de caça e lavouras produtivas ou por serem transmissores de doenças. Quanto às serpentes, são quase unanimemente consideradas perigosas, não ocorrendo distinção entre espécies peçonhentas e não-peçonhentas, sendo mortas por representarem risco à vida das pessoas e animais domésticos. Por outro lado, animais que geram conflitos também podem ser fontes de recursos para a população, sendo utilizados como alimento ou seus subprodutos (gordura, couro, língua, etc.) como remédios naturais, ornamentos e elementos mágico-religiosos.

Medidas que reduzam o contato entre animais silvestres potencialmente perigosos e o homem e suas criações domésticas são importantes na conservação dessas espécies conflituosas. Como exemplo, sugere-se a manutenção de animais domésticos isolados em currais e galinheiros, a construção de cercas por toda área de pastagem e o controle na deposição de lixo no entorno das propriedades rurais, principalmente próximo a áreas domiciliares, evitando que animais silvestres saiam de seu ambiente natural e invadam as propriedades rurais em busca de alimento. Além disso, estratégias de erradicação da caça predatória e esportiva e atividades comuns disseminadas na área estudada são fundamentais na redução do abate intensivo de animais silvestres. Apesar da caça esportiva ser uma questão cultural solidificada nos costumes locais, é através dela que o homem invade o ambiente natural dos animais, aumentando a chance de acidentes. Há também a necessidade de se implementar trabalhos de educação ambiental com o intuito de informar a população local da importância desses animais silvestres para o equilíbrio dos ecossistemas, a relevância dos mesmos na questão de saúde pública e, principalmente, ensinar as pessoas como lidar com eles no seu meio natural, reconhecendo as espécies potencialmente perigosas ao ser humano.

\section{Agradecimentos}

Aos moradores do município de Pocinhos, pela disponibilidade em ceder seu tempo e conhecimento para a realização desse trabalho. Ao Sr. João Evangelista Guimarães Mendonça, que acompanhou o primeiro autor em todas as visitas e coletas. À UEPB/PROPESQ (011/2008) e ao CNPq/ Edital Universal (472623/2009-5), pelo apoio financeiro. À CAPES, pela bolsa concedida ao primeiro e quarto autores. Ao CNPq, pela bolsa de produtividade concedida ao último autor. 


\section{REFERÊNCIAS}

Albuquerque, U.P.; Lucena, R. \& Alencar, N.L. 2010. Métodos e técnicas para coleta de dados etnobiológicos. In: U.P. Albuquerque, R.F.P. Lucena \& L.V.F.C. Cunha (orgs), Métodos e Técnicas na Pesquisa Etnobiológica e Etnoecológica. Editora Livro Rápido/NUPEEA, Recife, p. 39-64.

Alexander, B.; Carvalho, R.L.; McCallum, H. \& Pereira, M.H. 2002. Role of the domestic chicken (Gallus gallus) in the epidemiology of urban visceral leishmaniasis in Brasil. Emerging Infectious Diseases 8: 1480-1485.

Alvard, M.S.; Robinson, J.G.; Redford, K.H. \& Kaplan, H. 1997. The sustainability of subsistence hunting in the Neotropics. Conservation biology 11(4): 977-982.

Alves, R.R.N. \& Rosa, I.L. 2006. From cnidarians to mammals: the use of animals as remedies in fishing communities in NE Brazil. Journal of Ethnopharmacoly 107: 259-276.

Alves, R.R.N. \& Rosa, I.L. 2007. Zootherapeutic practices among fishing communities in North and Northeast Brazil: A comparison. Journal of Ethnopharmacology 111: 82-103.

Alves, R.R.N. \& Souto, W.M.S. 2010. Etnozoologia: conceitos, considerações e importância. In: R.R.N. Alves, W.M.S. Souto \& J.S. Mourão (orgs), Etnozoologia no Brasil: importância, status atual e perspectivas. Vol. 1. NUPEEA, Recife, p. 2140.

Alves, R.R.N.; Rosa, I.L. \& Santana, G.G. 2007. The role of animal-derived remedies as complementary medicine in Brazil. Bioscience 57: 949-955.

Alves, R.R.N.; Mendonça, L.E.T.; Confessor, M.V.A.; Vieira, W.L.S. \& Lopez, L.C.S. 2009. Hunting strategies used in the semi-arid region of northeastern Brazil. Journal of Ethnobiology and Ethnomedicine 5: 12.

Alves, R.R.N.; Mendonça, L.E.T.; Confessor, M.V.A.; Vieira, W.L.S.; Vieira, K.S. \& Alves, F.N. 2010a. Caça no Semiárido paraibano: uma abordagem etnozoológica. In: R.R.N. Alves, W.M.S. Souto \& J.S. Mourão (orgs), Etnozoologia no Brasil: importância, status atual e perspectivas. Vol. 1. NUPEEA, Recife, p. 349- 377.

Alves, R.R.N.; Nogueira, E.; Araújo, H. \& Brooks, S. 2010 b. Bird-keeping in the Caatinga, NE Brazil. Human ecology 38(1): 147-43.

Alves, R.R.N.; Pereira Filho, G.A.; Vieira, K.S.; Santana, G.G.; Vieira, W.L.S. \& Almeida, W.O. 2010c. Répteis e as populações humanas no Brasil: uma abordagem etnoherpetológica. In: R.R.N. Alves; W.M.S. Souto \& J.S. Mourão (orgs), Etnozoologia no Brasil: importância, status atual e perspectivas. Vol. 1. NUPEEA, Recife, p. 121-147.

Alves, R.R.N.; Barbosa, J.A.A.; Santos, L.D.X.S; Souto, W.M.S. \& Barboza, R.R.D. 2011. Animal-based remedies as complementary medicines in the semi-arid region of northeastern Brazil. Evidence-Based Complementary and Alternative Medicine: ID 179876.

Andreu, G.C. 2000. Mytos, leyendas y realidades de los reptiles de Mexico. Ciencia Ergo Sum 7(3): 286-291.

Andriguetto-Filho, J.M.; Krüger, A.C. \& Lange, M.B.R. 1998. Caça, biodiversidade e gestão ambiental na Área de Proteção Ambiental de Guaraqueçaba, Paraná, Brasil. Biotemas 11(2): 133-156.

Argôlo, A.J.S. 2004. As Serpentes dos Cacauais do Sudeste da
Bahia. Editora da UESC, Ilhéus.

Azevedo, F.C.C. \& Conforti, V.A. 2002. Fatores predisponentes à predação. In: M.R.P.L. Pitman, T.G. Oliveira, R.C. Paula \& C. Indrusiak (eds), Manual de Identificação, Prevenção $e$ Controle de Predação por Carnívoros. Edições IBAMA, Brasília, p. 27-28.

Bailey, K. 1994. Methods of Social Research. 4 ed. The Free Press, New York.

Baker, F.C. 1930. The use of animal life by the mound-building Indians of Illinois. Transations of the Illinois State Academy Society 22: 41-64.

Bangs, E. \& Shivik, J. 2001. Managing wolf conflict with livestock in the northwestern United States. Carnivore Damage Prevention News 3: 2-5.

Begossi, A. 1992. Food taboos at Búzios Island (Brazil): their significance and relation to folk medicine. Journal of Ethnobiology 12: 117-139.

Begossi, A. \& Braga, F.S.M. 1992. Food taboos and folk medicine among fishermen from the Tocantins River. Amazoniana 12: 10-118.

Bencke, G.A. 2001. Lista de Referência das Aves do Rio Grande do Sul. FZB-RS, Porto Alegre.

Bernard, R. 1994. Research Methods in Anthropology: qualitative and quantitative approaches. Sage Publications, Thousand Oaks.

Bizerril, M.X.A. 2004. Children's perceptions of Brazilian Cerrado landscapes and biodiversity. Journal of Environmental Education 35(4): 47-58.

Bodmer, R.E. \& Lozano, E.P. 2001. Rural development and sustainable wildlife use in Peru. Conservation Biology 15(4): 1163-1170.

Brady, C.A. 1979. Observations on the behavior and ecology of the crab-eating fox (Cerdocyon thous). In: J.F. Eisenberg (ed.), Vertebrate Ecology in the Northern Neotropics. Smithsonian Institution Press, Washington, D.C., p. 161-167.

Branch, L. \& Silva, M.F. 1983. Folk medicine in Alter do Chão, Pará, Brasil. Acta Amazonica 13: 737-797.

Brewer, D.D. 2002. Supplementary interviewing techniques to maximize output in free listing tasks. Field Methods 1: 108118.

Cardoso, J.L.C.; França, F.P.S.; Wen, F.H.; Málaque, C.M.S. \& Haddad-Jr, V. 2003. Animais Peçonhentos no Brasil: biologia, clínica e terapêutica dos acidentes. Sarvier, São Paulo, p. 150-159.

Carnieli, P.; Fahl, W.O.; Castilho, J.G.; Oliveira, R.N.O.; Macedo, C.I.M.; Durymanova, E.; Jorge, R.S.P.; Morato, R.G.; Spindola, R.O.; Machado, L.M.; Jeu, S.A.; Carrieri, M.L. \& Kotait, I. 2008. Characterization of Rabies virus isolated from canids and identification of the main wild canid host in northeastern Brazil. Virus Research 131: 33-46.

Carvalho Jr, O. \& Luz, N.C. 2008. Pegadas. Série boas práticas. Livro 3. Editora Universitária UFPA, Belém.

Cavalcanti, S.M.C.; Marchini, S.; Zimmermann, A; Gese, E.M. \& Macdonald, D.W. 2010. Jaguars, livestock, and people in Brazil: realities and perceptions behind the conflict. In: D.W. Macdonald \& A.J. Loveridge (eds), Biology and Conservation of Wild Felids. Oxford University Press, Oxford, p. 283-402. 
Cerqueira, E.J.; Sherlock, I.; Gusmão, A.; Barbosa, J.R.A.A. \& Nakatani, M. 2003. Experimental infection of Equus asinus with Leishmania chagasi Cunha \& Chagas, 1937. Revista da Sociedade Brasileira de Medicina Tropical 36(6): 695-701.

Cheida, C.C. 2006. Ordem Carnivora. In: N.R. Reis, A.L. Peracchi, W.A. Pedro \& I.P. Lima (eds), Mamíferos do Brasil. UEL, Londrina, p. 231-275

Chiarello, A.G.; Aguiar, L.M.S.; Cerqueira, R.; Melo, F.R.; Rodrigues, F.H.G. \& Silva, V.M. 2008. Mamíferos ameaçados de extinção no Brasil. In: A.B.M. Machado, G.M. Drummond \& A.P. Paglia (eds), Livro Vermelho da Fauna Brasileira Ameaçada de Extinção. Fundação Biodiversitas, Belo Horizonte, p. 697-874.

Confessor, M.V.A.; Mendonça, L.E.T.; Mourão, J.S. \& Alves, R.R.N. 2009. Animals to heal animals: ethnoveterinary practices in semi-arid region, northeastern Brazil. Journal of Ethnobiology and Ethnomedicine 5: 37.

Conforti, V.L. \& Azevedo, F.C.C. 2003. Local perceptions of jaguars (Panthera onca) and pumas (Puma concolor) in the Iguaçu National Park area, south Brazil. Biological Conservation 111: 215-221.

Conover, M. 2002. Resolving Human-Wildlife Conflicts: the science of wildlife damage management. Lewis Publishers, Boca Raton.

CPRM (Serviço Geológico do Brasil) 2005. Projeto cadastro de fontes de abastecimento por água subterrânea. Diagnóstico do Município de Pocinhos, Estado da Paraíba.

Courtenay, O.; Macdonald, D.W.; Lainson, R.; Shaw, J.J. \& Dye, C. 1994. Epidemiology of canine leishmaniasis: a comparative serological study of dogs and foxes in Amazon Brazil. Parasitology 109(3): 273-279.

Courtenay, O.; Santana, E.W.; Johnson, P.J.; Vasconcelos, I.A. \& Vasconcelos, A.W. 1996. Visceral leishmaniasis in the hoary zorro Dusicyon vetulus: a case of mistaken identity. Transactions of the Royal Society of Tropical Medicine and Hygiene 90(5): 498-502.

Curi, N. 2005. Avaliação do Estado de Saúde e do Risco de Transmissão de Doenças entre Canídeos (Mammalia, Carnívora) Silvestres e Domésticos na Região da Serra do Cipó, Minas Gerais: implicações para a conservação. Dissertação de mestrado. Pontifícia Universidade Católica de Minas Gerais.

Deane, L.M. \& Deane, M.P. 1955. Observações preliminares sobre a importância comparativa do homem, do cão e da raposa (Lycalopex vetulus) como reservatórios da Leishmania donovani em área endêmica de calazar no Ceará. Hospital 48: 61-76.

Eagles, P.F.J. \& Muffitts, S. 1990. The analysis of children's attitudes toward animals. Journal of Environmental Education 21(3): 41-44.

Facure, K.G. \& Monteiro-Filho, E.L.A. 1996. Feeding habits of the crab-eating fox, Cerdocyon thous (Carnivora, Canidae), in a suburban area of southeastern Brazil. Mammalia 60(1): 147-149.

Feitosa, R.F.G.; Melo, I.M.L.A. \& Monteiro, H.S.A. 1997. Epidemiologia dos acidentes por serpentes peçonhentas no estado do Ceará - Brasil. Revista da Sociedade Brasileira de Medicina Tropical 30(4): 295-301.

Fernades-Ferreira, H. 2011. Atividades Cinegéticas em um Brejo de Altitude no Nordeste do Brasil: etnozoologia e conservação. Dissertação de Mestrado. Universidade Federal da Paraíba.

Fiorello, C.V.; Noss, A.J.; Deem, S.L.; Maffei, L. \& Dubovi, E.J. 2007. Serorurvey of small carnivores in the Bolivian Chaco. Journal of Wildlife Diseases 43: 551-557.

Foloma, M. 2005. Impacto do Conflito Homem e Animais Selvagens na Segurança Alimentar na Provincia de Cabo Delgado. FAO, Moçambique.

Foster, M.S. \& James, S.R. 2002. Dogs, deer, or guanacos: zoomorphic figurines from Pueblo Grande, central Arizona. Journal of Field Archaeology 29(1): 165-176.

Franke, J. \& Telecky, T.M. 2001. Reptiles as Pets: an examination of the trade in live reptiles in the United States. Humane Society of the United States, Washington, DC.

Galetti, M. \& Rodrigues, M. 1992. Comparative seed predation on pods by parrots in Brazil. Biotropica 24: 222-224.

Greene, H. 1997. Snakes: the evolution of mystery in nature. University of California Press, Berkeley.

Guggisberg, C.A.W. 1975. Wild Cats of the World. Taplinger Publishing Company, New York.

Hanazaki, N.; Alves, R. \& Begossi, A. 2009. Hunting and use of terrestrial fauna used by Caiçaras from the Atlantic Forest coast (Brazil). Journal of Ethnobiology and Ethnomedice 5(1): 36.

Hays, T.E. 1976 An empirical method for the identification of covert categories in ethnobiology. American Ethnologist 3(3): 489-507

Hill, K. \& Padwe, J. 2000. Sustainability of ache hunting in the Mbaracayu Reserve, Paraguay. In: J.G. Robinson \& E.L. Bennett (eds), Hunting for Sustainability in Tropical Forests. Columbia Press, New York, p. 79-105.

Hoogesteijn, R.; Hoogesteijn, A. \& Mondolfi, E. 1993. Jaguar predation and conservation: cattle mortality caused by felines on three ranches in the Venezuelan Llanos. Symposium of the Zoological Society of London (65): 391-407.

Hoover, C. 1998. The US Role in the International Live Reptile Trade: Amazon tree boas to Zululand dwarf chameleons. TRAFFIC North America, Washington.

Hurtado, L.C. 2007. Avaliação da Predação de Criações Domésticas por Lobo-Guará (Chrysocyon brachyurus) no Entorno do Parque Nacional da Serra da Canastra, MG, Brasil. Dissertação de mestrado. Universidade Federal de Minas Gerais.

IBGE (Instituto Brasileiro de Geografia e Estatística) 2006. Senso Agropecuário 2006. Disponível em http//www.ibge.com.br; acesso em 28 abr. 2011.

IBGE (Instituto Brasileiro de Geografia e Estatística) 2010. Senso Demográfico 2010. Disponível em http://www.ibge.gov.br/ cidadesat/topwindow.htm?1; acesso em 28 abr. 2011.

IUCN (International Union for Conservation of Nature) 2011. The IUCN Red List of Threatened Species. Disponível em http://www.iucnredlist.org; acesso em 28/04/2011.

Jackson, R.M.; Ahlborn, G.G.; Gurung, M. \& Ale, S. 1996. Reducing livestock depredation in the Nepalese Himalayas. Proceedings of the Vertebrate Pest Conference 17: 241-247.

Jansen, A.M.; Leon, L.; Machado, G.M.; Silva, M.H.; SouzaLeão, S.M. \& Deane, M.P. 1991. Trypanosoma cruzi in opossum Didelphis marsupialis: parasitological and serological follow-up of the acute infection. Experimental Parasitology 73: 249-259.

Jansen, A.M.; Madeira, F.; Carreira, C.J.; Medina-Acosta, 
E. \& Deane, M.P. 1997. Trypanosoma cruzi in the opossum Didelphis marsupialis: a study of the correlations and kinetics of the systemic and scent gland infections in naturally and experimentally infected animals. Experimental Parasitology 86: 37-44.

Janzen, D.H. 1981. Ficus ovalis seed predation by orange-chinned parakeet (Brotogeris jugularis) in Costa Rica. Auk 98: 841844.

Jorge, R.S.P. 2008. Caracterização do Estado Sanitário dos Carnívoros Selvagens da RPPN SESC Pantanal e de Animais Domésticos da Região. Tese de Doutorado. Universidade de São Paulo.

Kaltenborn, T.; Bjerke, B.T. \& Nyahongo, J. 2006. Living with problem animals - self-reported fear of potentially dangerous species in the Serengeti region, Tanzania. Human Dimensions of Wildlife 11: 397-409.

Lainson, R.; Shaw, J.J.; Miles, M.A. \& Povoa, M. 1982. Leishmaniasis in Brazil: XVII. Enzymic characterization of a Leishmania from the armadillo, Dasypus novemcinctus (Edentata), from Para State. Transactions of the Royal Society of Tropical Medicine and Hygiene 76(6): 810811.

Lainson, R.; Dye, C.; Shaw, J.J.; Macdonald, D.W.; Courtenay, O.; Souza, A.A. \& Silveira, F.T. 1990. Amazonian visceral leishmaniasis - distribution of the vector Lutzomyia longipalpis (Lutz \& Neiva) in relation to the fox Cerdocyon thous (Linn.) and the efficiency of this reservoir host as source of infection. Memórias do Instituto Oswaldo Cruz, 85(1): 135-137.

Langguth, A. 1975. Ecology and evolution in the South American canids. In: M.W. Fox (ed.), The Wild Canids: their systematics, behavioral ecology, and evolution. Van Nostrand Reinhold Co., New York, p. 192-206.

Leal, I.R.; Silva, J.M.C.; Tabarelli, M. \& Lacher, J.R.T.E. 2005. Mudando o curso da conservação da biodiversidade na Caatinga do Nordeste do Brasil. Megadiversidade 1(1): 139146.

Lisboa, P. (org.). 2002. Natureza, homem e manejo de recursos naturais na região de Caxiuanã, Melgaço, Pará. MPEG, Belém.

Llanos-Cuentas, E.A. 1999. Natural infections of Leishmania peruviana in animals in the Peruvian Andes. Transactions of the Royal Society of Tropical Medicine and Hygiene 93(1): 1520.

Lourival, R.F.F. \& Fonseca, E.G.B. 1997. Análise de sustentabilidade do modelo de caça tradicional, no Pantanal da Nhecolândia, Corumbá, MS. In: C.V. Pádua \& R.E. Bodmer (eds), Manejo e Conservação de Vida Silvestre no Brasil. Sociedade Civil Mamirauá/CNPq, Brasília

Marcum, H. 2007. Living with animals: snakes and humans. Encyclopedia of Human-Animal Relationships: a global exploration of our connections with animals. Greenwood Press, Westport, p. 1181-1184.

Marques, J.G.W. 1991. Aspectos Ecológicos na Etnoictiologia dos Pescadores do Complexo Estuarino-Lagunas MundaúManguaba. Tese de Doutorado. Universidade Estadual de Campinas.

Marques, J.GW. 1995. Pescando Pescadores: etnoecologia abrangente no Baixo São Francisco. NUPAUB-USP, São Paulo.

Mazzolli, M.; Graipel, M.E. \& Dunstone, N. 2002. Mountain lion depredation in southern Brazil. Biological Conservation 105: 43-51.

Mello, L.G. 2003. Antropologia Cultural. Editora Vozes, Rio de Janeiro.

Michalski, F.; Boulhosa, R.L.P.; Faria, A. \& Peres, C.A. 2006. Human-wildlife conflicts in a fragmented Amazonian forest landscape: determinants of large felid depredation on livestock. Animal Conservation 9: 179-188.

Mills, J.N. \& Childs, J.E. 1998. Ecologic studies of rodent reservoirs: their relevance for human health. Emerging Infectious Diseases 4: 529-537.

Mohebali, M.; Hajjaran, H.; Hamzavi, Y.; Mobedi, I.; Arshi, S.; Zarei, Z.; Akhoundi, B.; Naeini, K.M.; Avizeh, R. \& Fakhar, M. 2005. Epidemiological aspects of canine visceral leishmaniosis in the Islamic Republic of Iran. Veterinary Parasitology 129(3-4): 243-51.

Morris, R. \& Morris, D. 1965. Men and Snakes. London, Hutchinson.

Motta-Júnior, J.C.; Lombardi, J.A. \& Talamoni, S.A. 1994. Notes on crabeating fox (Dusicyon thous) seed dispersal and food habits in southeastern Brazil. Mammalia 58: 156-159.

Moura, R.M.; Costa, C.H.; São Pedro, C.A.; Fernandes, D.V. \& Feio, R.N. 2010. O relacionamento entre pessoas e serpentes no Leste de Minas Gerais, Sudeste do Brasil. Biota Neotropica 10(4): 133-142.

Naughton-Treves, L. 1998. Predicting patterns of crop damage by wildlife around Kibale National Park, Uganda. Conservation Biology 12: 156-168.

Naughton-Treves, L. \& Treves, A. 2005. Socio-ecological factors shaping local support for wildlife: crop-raiding by elephants and other wildlife in Africa. In: R. Woodroffe, S. Thirgood \& A. Rabinowitz (eds), People and Wildlife: conflict or coexistence? Cambridge University Press, Cambridge, p. 252277.

Newmark, W.D.; Manyanza, D.N.; Gamassa, D.M. \& Sariko, H.I. 1994. The conflict between wildlife and the local people adjacent to protected areas in Tanzania: human density as a predictor. Conservation Biology 8(1): 249-255.

Nie, M. 2001. The socio-political dimensions of wolf management and restoration in the United States. Human Ecology 8: 112.

Nobre, R. 2007. Modelos de Sustentabilidade de Caça na Serra do Mar, Mata Atlântica. Dissertação de mestrado. Universidade de São Paulo.

Oli, M.K.; Taylor, I.R. \& Rodgers, M.E. 1994. Snow leopard Panthera uncia predation of livestock: an assessment of local perceptions in the Annapurna Conservation Area, Nepal. Biological Conservation 68: 63-68.

Oliveira, E.S.; Torres, D.F.; Brooks, S.E. \& Alves, R.R.N. 2010. The medicinal animal markets in the metropolitan region of Natal City, northeastern Brazil. Journal of Etnopharmacology 130: 54-60.

Oliveira, T.G. \& Cassaro, E.K. 2005. Guia de Campo dos Felinos do Brasil. Instituto Pro-Carnivoros/Fundação Parque Zoológico de São Paulo/Sociedade de Zoológicos do Brasil/ Pro-Vida Brasil, São Paulo.

Oliver, J.A. 1968. Snakes in Fact and Fiction. The Macmillian Company, New York.

Olmos, F. 1993. Notes on the food habits of Brazilian Caatinga carnivores. Mammalia 57: 126-130.

Packer, C.; Ikanda, D.; Kissui, B. \& Kushnir, H. 2005. Lion 
attacks on humans in Tanzania. Nature 436: 927-928.

Patterson, I.J.; Abdul Jalil, S. \& East, M.L. 1989. Damage to winter cereals by greylag and pink-footed geese in north-east Scotland. Journal of Applied Ecology 26: 879-895.

Perez, E. \& Pacheco, L.F. 2006. Damage by large mammals to subsistence crops within a protected area in a montane forest of Bolivia. Crop Protection 25: 933-939.

Pitman, M.R.P.L.; Oliveira, T.G.; Paula, R.C. \& Indrusiak, C. (eds) 2002. Manual de Identificação, Prevenção e Controle de Predação por Carnívoros. Edições IBAMA, Brasília.

Polisar, J.; Matix, I.; Scognamillo, D.; Farrell, L.; Sunquist, M.E. \& Eisenberg, J.F. 2003. Jaguars, pumas, their prey base, and cattle ranching: ecological interpretations of a management problem. Biological Conservation 109: 297310.

Quigley, H.B.E.P.G. \& Crawshaw, J.R. 1992. A conservation plan for the jaguar Panthera Onca in the Pantanal region of Brazil. Biological Conservation 61(3): 149-157.

Quigley, H.B. \& Herrero, S. 2005. Characterization and prevention of attacks on humans. In: R. Woodroffe, S. Thirgood \& A. Rabinowitz (eds), People and Wildlife: conflict or co-existence? Cambridge University Press, Cambridge, p. $27-49$.

Rabinowitz, A.R. 1986. Jaguar predation on domestic livestock in Belize. Wildlife Society Bulletin 14: 170-174.

Rao, K.S.; Maikhuri, R.K.; Nautiyal, S. \& Saxena, K.G.. 2002. Crop damage and livestock depredation by wildlife: a case study from Nanda Devi Biosphere Reserve, India. Journal of Environmental Management 66: 317-327.

Redford, K.H. 1992. The empty forest. Bioscience 42(6): 412423.

Renton, K. 2001. Lilac-crowned parrot diet and food resource availability: resource tracking by a parrot seed predator. Condor 103: 62-69.

Rezende, J.P. \& Schiavetti, A. 2010. Conhecimentos e usos da fauna cinegética pelos caçadores indígenas "Tupinambá de Olivença” (Bahia). Biota Neotropica 10(1): 175-183.

Ribeiro, R.S. 2003. Pocinhos: o local e o geral. RG Gráfica e Editora, Campina Grande.

Rinaldi, A.R. 2010. Dieta de Pequenos Felinos Silvestres (Carnivora, Felidae), em Área Antropizada de Mata Atlântica de Interior, Alto Rio Paraná, Paraná, Brasil. Dissertação de mestrado. Universidade Federal do Paraná.

Rocha, V.J.; Reis, N.R. \& Sekiama, M.L. 2004. Dieta e dispersão de sementes por Cerdocion thous (Linnaeus) (Carnivora, Canidae), em um fragmento florestal do Paraná, Brasil. Revista Brasileira de Zoologia 21(4): 871-876.

Rosas, G.K.C. 2006. Pressão de Caça, Abundância, Densidade e Riqueza de Mamíferos em Duas Áreas de Coleta de Castanhado-Brasil Situadas no Sudoeste do Estado do Acre, Brasil. Tese de doutorado. Universidade Federal do Acre.

Ruelle, P. \& Bruggers, R.L. 1982. Traditional approaches for protecting cereal crops from birds in Africa. In: Proceedings of the Tenth Vertebrate Pest Conference, University of Nebraska, Lincoln, p. 80-86.

Sagor, J.T.; Swenson, J.E. \& Roskaft, E. 1997. Compatibility of brown bear Ursus arctos and free-ranging sheep in Norway. Biological Conservation 81: 91-95.

Saj, T.L.; Sicotte, P. \& Paterson, J.D. 2001. The conflict between vervet monkeys and farmers at the forest edge in Entebbe, Uganda. African Journal of Ecology 39: 195-199.
Santos-Fita, D.S.; Costa Neto, E.M. \& Schiavetti, A. 2010 'Offensive' snakes: cultural beliefs and practices related to snakebites in a Brazilian rural settlement. Journal of Ethnobiology and Ethnomedicine 6: 13.

Sanyal, P. 1987. Managing the man-eaters in the Sundarbans tiger reserve of India: a case study. In: R.L. Tilson \& U. S. Seal (eds), Tigers of the World: the biology, biopolitics, management and conservation of an endangered species. Noyes Publications, New Jersey, p. 427-434.

Schaller, G.B. 1976. Notes on the Large Mammals of Parque Nacional das Emas, Brazil. Report to IBDF.

Schober, J. 2002. Preservação e uso racional do único bioma exclusivamente nacional. Ciência e Cultura 54(2): 6-7.

Sekhar, N.U. 1998. Crop and livestock depredation caused by wild animals in protected areas: the case of Sariska Tiger Reserve, Rajasthan, India. Environmental Conservation 25: 160-171.

Sherlock, I.A. 1996. Ecological interactions of visceral leishmaniasis in the state of Bahia, Brazil. Memória do Instituto Oswaldo Cruz 91(6): 671-83.

Sherlock, I.A.; Miranda, J.C.; Sadigursky, M. \& Grimaldi Junior, G. 1984. Natural infection of the opossum Didelphis albiventris (Marsupialia, Didelphidae) with Leishmania donovani, in Brazil. Memória do Instituto Oswaldo Cruz 79(4): 511.

Sick, H. 1997. Ornitologia Brasileira. Editora Nova Fronteira, Rio de Janeiro.

Sillero-Zubiri, C. \& Laurenson, M.K. 2001. Interactions between carnivores and local communities: conflict or coexistence? In: J.L. Gittleman, S.M. Funk, D.W. Macdonald \& R.K. Wayne (eds), Carnivore Conservation. Cambridge University Press, Cambridge, p. 282-312.

Silva, M.V. 2006. Serpentes do Estado do Acre: riqueza, dieta, etnoconhecimento e acidentes ofídicos. Dissertação de mestrado. Universidade Federal do Acre.

Silveira, F.T.; Lainson, R.; Shaw, J.J. \& Povoa, M.M. 1982 Leishmaniasis in Brazil: XVIII. Further evidence incriminating the fox Cerdocyon thous as a reservoir of Amazonian visceral leishmaniasis. The Royal Society of Tropical Medicine H 76: 830-832.

Silveira, L. 1999. Ecologia e Conservação dos Mamíferos Carnívoros do Parque Nacional das Emas, Goiás. Dissertação de mestrado. Universidade Federal de Goiás.

Silvius, K.M.; Bodmer, R.E. \& Fragoso, J.M.V. 2004. People in Nature: wildlife conservation in South and Central America. Columbia University Press, New York.

Souto, W.M.S.; Mourão, J.S.; Barboza, R.R.D. \& Alves, R.R.N. 2011. Parallels between zootherapeutic practices in ethnoveterinary and human complementary medicine in northeastern Brazil. Journal of Ethnopharmacology 134(3):753-767.

Souza-Junior, M.F.; Lobato, Z.I.P. \& Lobato, F.C.F. 2006. Presença de anticorpos da classe IgM de Leptospira interrogans em animais silvestres do estado do Tocantins, Revista da Sociedade Brasileira de Medicina Tropical 39: 292-294.

Stahl, P. \& Vandel, J.M.L. 2001. Factors influencing lynx depredation on sheep in France: problem individuals and habitat. Carnivore Damage Prevention News 4: 6-8.

Stahl, P.; Vandel, J.M.; Herrenschmidt, V. \& Migot, P. 2001. Predation on livestock by an expanding reintroduced lynx 
population: long-term trend and spatial variability. Journal of Applied Ecology 38: 674-687.

Stebbins, R.A. 1987. Fitting in: the researcher as learner and participant. Quality and Quantity 21(1): 103-108.

Thirgood, S.; Woodroffe, R. \& Rabinowitz, A. 2005. The impact of human-wildlife conflict on human lives and livelihoods. In: R. Woodroffe, S. Thirgood \& A. Rabinowitz (eds), People and Wildife: conflict or co-existence? Cambridge University Press, Cambridge, p. 13-26.

Treves, A.; Naughton-Treves, L.; Harper, E.K.; Mladenoff, D.J.; Rose, R.A.; Sickley, T.A. \& Wydeven, A.P. 2004. Predicting human-carnivore conflict: a spatial model derived from 25 years of data on wolf predation on livestock. Conservation Biology 18(1): 114-125.

Trinca, C.T. \& Ferrari, S.F. 2006. Caça em assentamento rural na Amazônia matogrossense. In: P. Jacobi \& L.C. Ferreira (orgs), Diálogos em Ambiente e Sociedade no Brasil. ANPPAS, Annablume, Indaiatuba, p. 155-167.

Vargas, L.M.A. 2002. Estudio Comparativo de la Caza y Uso de Mamíferos en dos Comunidades Tsimane'. Monografia. Universidad Mayor de San Andrés.

Vieira, W.L.S. 2011. Riqueza de Espécies e Utilização de Recursos em uma Taxocenose de Squamata em Caatinga Arbórea na Região do Cariri, Paraíba, Brasil. Tese de doutorado. Universidade Federal da Paraíba.
Vitousek, P.M.; Mooney, H.A.; Lubchenco, J. \& Melillo, J.M. 1997. Human Domination of Earth's Ecosystems. Science 277: 494-499.

Vizotto, L.D. 2003. Serpentes: lendas, mitos, superstições $e$ crendices. Plêidade, São Paulo.

Weladji, R.B. \& Tchamba, M.N. 2003. Conflict between people and protected areas within the Bénoué Wildlife. Oryx 37(1): 72-79.

Weller, S.C. \& Romney, A.K. (eds) 1988. Systematic Data Collection. Sage Publications, Newbury Park.

Woodroffe, R. 2000. Predators and people: using human densities to interpret declines of large carnivores. Animal Conservation 3: 165-173.

Yom-Tov, Y.; Ashkenazi, S. \& Viner, O. 1995. Cattle predation by the golden jackal Canis aureus in the Golan Heights, Israel. Biological Conservation 73:19-22.

Zerpa, O.; Ulrich, M.; Benitez, M.; Avila, C.; Rodriguez, V.; Centeno, M.; Belizario, D.; Reed, S.G. \& Convit, J. 2002. Epidemiological and immunological aspects of human visceral leishmaniasis on Margarita Island, Venezuela. Memória do Instituto Oswaldo Cruz 97(8): 1079-1083.

Zimmermann, A.; Walpole, M.J. \& Leader-Williams, N. 2005. Cattle ranchers' attitudes to conflicts with jaguars in the Pantanal of Brazil. Oryx 39: 406-412. 